\title{
EFEKTIVITAS SCIENTIFIC APPROACH WITH GUIDED EXPERIMENT PADA PEMBELAJARAN IPA UNTUK MEMBERDAYAKAN KETERAMPILAN PROSES SAINS SISWA SEKOLAH DASAR
}

\author{
Pinkan Amita Tri Prasasti \\ Universitas PGRI Madiun \\ pinkan.amita@universitaspgrimadiun.ac.id
}

\begin{abstract}
The purpose of this study was to determine the effectiveness of Scientific Approach with Guided Experiment on learning science to empower Science Process Skills. This study is a quasiexperimental research. The study design used Posttest Only Control Group Design is divided into two groups: an experimental group using a Scientific Approach with Guided Experiment and control groups using the method of lecture and discussion. The population in the study were all students of class V SD SD N Banjarejo Academic Year 2016/2017 by the number of 122 students. The sampling technique is cluster random sampling done by taking a sample of 37 fifth grade students in the experimental class $A$ and 36 students of class $V C$ in the control class. The instrument used was a questionnaire, observation sheets, interview and test. Data science process skills were tested by t-test. The results of the analysis of hypothesis testing using t-test with significance level of 5\% yield significance at $p=0.000$ and the value $=0.018$. Classes that implement Scieintific aproach with Guided Experiment has an average KPS higher than the class without using Scieintific aproach with Guided Experiment in the amount of 82.34 and 71.14. Based on the results of hypothesis testing can dismpulkan that Scieintific aproach with Guided Experiment in empowering capabilities of Science Process Skills Student GradeV SD N Banjarejo Madiun Academic Year 2016/2017.
\end{abstract}

Keywords: Scientific Approach, Guided Experiment, Science Process Skills (SPS)

\section{Pendahuluan}

IPA (Ilmu Pengetahuan Alam) merupakan salah satu mata pelajaran untuk meningkatkan kemampuan berpikir rasional. Menurut Trianto (2014), IPA pada hakikatnya dibangun atas dasar produk ilmiah, proses ilmiah, dan juga sikap ilmiah. IPA memberdayakan siswa agar mempunyai pengetahuan, gagasan dan konsep yang terorganisasi tentang alam sekitar, yang diperoleh dari pengalaman melalui serangkaian proses ilmiah. Sebagai proses ilmiah diartikan semua kegiatan ilmiah untuk menyempurnakan pengetahuan tentang alam maupun untuk menemukan pengetahuan baru. Jelas bahwa proses belajar IPA ditekankan pada pendekatan keterampilan proses, hingga siswa dapat menemukan fakta, membangun konsep, teori dan sikap ilmiah sehingga tercapai tujuan pembelajaran.

Tercapainya tujuan dari pembelajaran dapat dilihat dari Keterampilan Proses Sains selama pembelajaran yang didukung oleh hasil belajar yang diperoleh siswa setelah melalui proses belajar. Sanjaya (2012: 30) menyatakan bahwa hasil belajar sebagai kriteria keberhasilan suatu sistem pembelajaran. Penguasaan Keterampilan Proses Sains yang baik akan menghasilkan hasil belajar maksimal. 
Pendekatan keterampilan proses sains (KPS) merupakan pendekatan pembelajaran yang berorientasi pada proses IPA. Menurut Trianto (2013: 144), ketrampilan proses sains merupakan keseluruhan ketrampilan ilmiah yang terarah yang dapat digunakan untuk menemukan suatu prinsip atau teori, untuk mengembangkan teori yang sudah ada sebelumnya ataupun untuk melakukan penyangkalan terhadap suatu penemuan/flasisikasi.

Berdasarkan hasil TIMMS (Trends in Mathematics and Science Study) tahun 2011, penilaian yang dilakukan International of Education Achievement Study Center Bostos College tersebut, Kemendikbud (2012: 37) menunjukkan bahwa Indonesia berada di urutan ke-40 dengan skor 406 dari 42 negara di bidang sains. Skor tes sains siswa Indonesia ini turun 21 angka dibandingkan TIMSS 2007. Sedangkan pada survey yang dilakukan oleh Programme for International Student Assesmen (PISA) tahun 2015, Organization for Economic Cooperation and Development (OECD) mengemukakan bahwa Indonesia menempati peringkat ke-69 dari 76 negara di bidang science. Meskipun begitu, Indonesia mengalami peningkatan kompetensi sains dari 382 poin pada tahun 2012 menjadi 403 poin di tahun 2015.

Hal tersebut membuktikan bahwa proses sains masih belum optimal. Para guru belum sepenuhnya melaksanakan pembelajaran secara aktif dan kreatif dalam melibatkan siswa serta belum menggunakan berbagai pendekatan pembelajaran yang bervariasi berdasarkan karakter materi pelajaran. Dalam proses belajar mengajar, kebanyakan guru hanya terpaku pada buku sebagai satu- satunya sumber belajar mengajar. Hal tersebut menjadi kelemahan dalam pembelajaran IPA dalam masalah teknik penilaian pembelajaran yang tidak akurat dan menyeluruh. Penyebab utama kelemahan pembelajaran tersebut adalah karena kebanyakan guru tidak melakukan kegiatan pembelajaran dengan memfokuskan pada pengembangan keterampilan proses sains anak.

Sains sebagai suatu proses atau cara untuk menemukan solusi terhadap suatu masalah atau memahami suatu fenomena (kejadian) di alam ini. Masalah atau kasus yang berhubungan dengan fenomenafenomena serta pengalaman yang dialami siswa membuat pembelajaran lebih bermakna sehingga siswa akan terpengaruh untuk melakukan kegiatan ilmiah. Metode ilmiah yang dikembangkan untuk SD dilakukan secara bertahap dan berkesinambungan dengan harapan bahwa pada akhirnya akan terbentuk paduan yang lebih utuh sehingga siswa dapat melakukan penelitian sederhana.

Berdasarkan observasi yang dilakukan peneliti di SDN Banjarejo Kota Madiun, diketahui bahwa rata-rata nilai pada mata pelajaran IPA setara dengan standar ketuntasan lulusan (SKL). Hal ini menunjukkan bahwa diperlukan upaya untuk meningkatkan kemampuan sikap, pengetahuan dan keterampilan bagi siswa untuk meningkatkan dan mengembangkan keterampilan siswa terutama dalam pembelajaran IPA.

Hasil observasi dari 8 Standar Nasional Pendidikan yang dikeluarkan oleh BSNP memiliki prosentase nilai yang tergolong rendah daripada standart yang lain adalah 
standart proses pembelajaran yaitu sekitar 78 $\%$. Hal ini didukung fakta berdasarkan observasi awal pada kelas V SDN Banjarejo, ada beberapa permasalahan yang ditemukan diantaranya pembelajaran IPA yang berlangsung hanya berfokus pada Minds On dan mengesampingkan Hands On dimana pembelajarannya masih dominan mendengarkan penjelasan guru dan menghafal. Selain itu, siswa hanya melakukan kegiatan eksperimen di kelas hanya 3 kali dalam 1 semester. Idealnya kegiatan eksperimen dilakukan pada setiap KD disesuaikan dengan karakteristik materi pembelajaran. Kualitas pembelajaran yang buruk menyebabkan hampir $75 \%$ siswa yang memperoleh nilai di bawah KKM diduga karena Keterampilan Proses Sains siswa pada mata pelajaran IPA masih rendah. Hal ini karena model pembelajaran yang selama ini digunakan oleh guru belum dapat memfasilitasi peserta didik untuk meningkatkan keterampilan selama proses pembelajaran.

Trianto (2014: 148) mengemukakan bahwa keterampilan-keterampilan proses perlu diajarkan agar memberikan penekanan pada keterampilan berpikir yang dapat berkembang pada diri siswa. Dengan mengembangkan keterampilan-keterampilan proses sains, maka anak akan mampu menemukan dan mengembangkan sendiri sebuah fakta atau konsep serta menumbuhkan sikap yang diperlukan dalam penemuan ilmu pengetahuan. Pemberdayaan KPS dapat dilakukan dengan pengembangan proses belajar yang mengarah pada proses kegiatan ilmiah salah satunya mengaplikasikan Scientific Aproach.
Scientific Aproach merupakan pendekatan di dalam kegiatan pembelajaran yang mengutamakan kreativitas dan temuantemuan peserta didik. Pengalaman belajar yang peserta didik dapat tidak bersifat indoktrinisasi, hafalan, dan sejenisnya (Capay, 2013). Scientific Aproach dimaksudkan untuk memberikan pemahaman kepada peserta didik dalam mengenal, memahami berbagai materi dengan menggunakan pendekatan ilmiah, bahwa informasi bisa berasal dari mana saja, kapan saja, tidak tergantung dari informasi searah yang diberikan oleh guru (Wenning: 2008). Oleh karena itu proses pembelajaran yang diharapkan tercipta diarahkan untuk mendorong peserta didik dalam mencari tahu dari berbagai sumber melalui observasi, dan tidak hanya diberi tahu. Berdasarkan penelitian Amita (2016) bahwa penggunaan Scieintific aproach pada pembelajaran sains dengan memeilliki efektivitas tinggi memeberdayakan KPS sesuai dengan tahapan dalam pembelajaran menekankan siswa menemukan sendiri konsep yang dipelajari, hal ini sejalan dengan teori belajar Jean Piaget bahwa siswa aktif mengkonstruksi secara terus menerus, sehingga terjadi pemahaman konsep ilmiah.

Scientific Aproach dapat dikembangkan dengan pengaplikasikan metode pembelajaran untuk mengoptimalkan dalam pemberdayaan KPS. Metode yang digunakan tentu metode pembelajaran yang menekankan pada pelatihan proses belajar melalui keterampilan salah satunya adalah mengguankan metode Guided Experiment. Guided Experiment adalah eksperimen terbimbing yaitu metode dimana seluruh jalannya percobaan sudah dirancang oleh 
guru sebelum dilakukan oleh siswa (Suparno, 2008), dengan metode ini siswa diharapkan: 1) Dapat mempelajari sains dengan pengamatan langsung terhadap gejala-gejala maupun proses-proses sains 2) Dapat melatih keterampilan berpikir ilmiah, 3) Dapat menanamkan dan mengembangkan sikap ilmiah, 4) Dapat menemukan dan memecahkan berbagai masalah baru melalui metode ilmiah dan lain sebagainya. Selain itu eksperimen terbimbing dapat membantu pemahaman siswa terhadap pelajaran. Penerapan Scientific approach berbasis Guided Experiment ini harus sesuai dengan materi yang diajarkan sehingga memberikan pengaruh yang positif terhadap Keterampilan Proses Sains siswa.

\section{Metode Penelitian}

Penelitian ini dilaksanakan di SD Negeri Banjarejo 2016/2017. Desain penelitian menggunakan Posttest Only Control Group Design yang terbagi menjadi dua kelompok yaitu kelompok ekperimen menggunakan Scientific Approach with Guided Experiment dan kelompok kontrol menggunakan metode ceramah dan diskusi. Populasi dalam penelitian adalah seluruh siswa SD kelas V SD N Banjarejo Tahun Akademik 2016/2017 dengan jumlah 122 siswa. Teknik pengambilan sampel dilakukan secara cluster random sampling dengan pengambilan sampel sejumlah 37 siswa kelas V A pada kelas eksperimen dan 36 siswa kelas V C pada kelas kontrol. Variabel bebas adalah Scieintific Aproach with Guided Experiment. Variabel terikat adalah ketrampilan proses sains. Teknik pengumpulan data menggunakan tes, dokumentasi, observasi, wawancara dan angket.

Uji validitas meliputi validitas isi dan validitas konstruk melalui judgment experts dan validitas butir soal korelasi product moment dari Karl Pearson. Uji reliabilitas menggunakan rumus Alfa ronbach, uji normalitas menggunakan KolmogorovSmirnov, uji homogenitas menggunakan Levene's, uji hipotesis menggunakan t-test menggunakan bantuan SPSS 20 dengan taraf signifikansi $5 \%$.

\section{HASIL PENGAMATAN DAN PEMBAHASAN}

Hasil uji efektivitas scieintific aproach dengan setting Problem Based Learning untuk memberdayakan mahasiswa diperoleh dari data Science Process Skill melalui uji hipotesis dan rerata Hasil uji hipotesis data Science Process Skill disajikan pada Tabel 1.

Tabel 1. Hasil Uji Hipotesis SPSS

\begin{tabular}{|c|c|c|c|c|c|}
\hline $\mathrm{Uji}$ & Kelas & Jenis Uji & Hasil & Keputusan & $\begin{array}{l}\text { Kesimpu } \\
\text { lan }\end{array}$ \\
\hline \multirow[t]{2}{*}{ Normalitas } & $\begin{array}{l}\text { Eksperime } \\
\mathrm{n}\end{array}$ & $\begin{array}{l}\text { Kolmogo } \\
\text { rof } \\
\text { Smirnov }\end{array}$ & $\begin{array}{l}\text { Sig } \\
\text { posttest= } \\
0,063\end{array}$ & Ho diterima & $\begin{array}{l}\text { Data } \\
\text { normal }\end{array}$ \\
\hline & Kontrol & & $\begin{array}{l}\text { Sig } \\
\text { posttest= } \\
0,071\end{array}$ & Ho diterima & $\begin{array}{l}\text { Data } \\
\text { normal }\end{array}$ \\
\hline Homogenitas & $\begin{array}{l}\text { Eksperime } \\
\mathrm{n} \\
\text { Kontrol }\end{array}$ & $\begin{array}{l}\text { Levene's } \\
\text { test }\end{array}$ & Sig 0.077 & Ho diterima & $\begin{array}{l}\text { Data } \\
\text { homogen }\end{array}$ \\
\hline Uji Hipotesis & $\begin{array}{l}\text { Eksperime } \\
\text { n } \\
\text { Kontrol }\end{array}$ & $U_{j i-T}$ & $\begin{array}{l}\mathrm{t}_{\text {hitung }}= \\
0,004 \\
\mathrm{p}=0,000\end{array}$ & Ho ditolak & $\begin{array}{l}\text { Ada } \\
\text { beda }\end{array}$ \\
\hline
\end{tabular}

Nilai Keterampilan proses sains menunjukkan bahwa nilai rata-rata pada kelas ekperimen sebesar 82,34 dan pada kelas kontrol menunjukan nilai rata-rata 71,14. Hal ini menunjukan bahwa Keterampilan proses sains siswa memiliki 
perbedaan dengan adanya pembelajaran menggunkan Scieintific Aproach pada pembelajaran sains dengan setting Problem Based Learning dibandingkan dengan penggunaan metode ceramah dengan mengaplikasikan diskusi.

Berdasarkan hasil penelitian dapat dibuat histogram rata-rata perbandingan Science Process Skill kelas ekperimen dan kelas kontrol seperti pada Gambar.1 dan perbandingan persentase penilain aspek

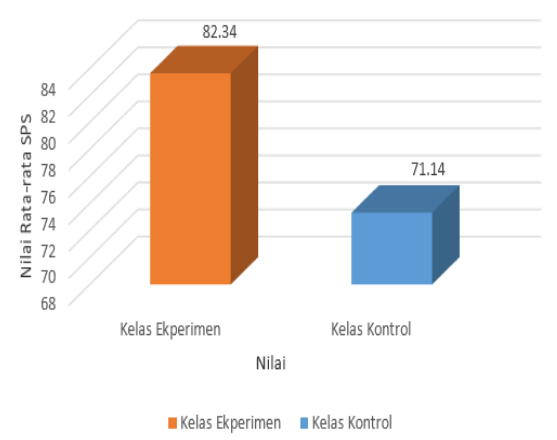

Gambar.1 Perbandingan Rata-rata Nilai Science Process Skill Kelas Ekperimen dan Kelas Kontrol

Berdasarkan hasil analisis uji-t dapat diketahui bahwa terdapat perbedaan yang signifikan antara nilai posttest kelas ekperimen dan kelas kontrol terkait kemampuan KPS. Kesimpulan dari hasil uji analisis terdapat perbedaan kemampuan KPS siswa pada kelas ekperimen dengan menggunakan Scieintific Aproach with Guided Experiment dan kelas kontrol yang menggunakan metode ceramah diskusi. Hasil rerata nilai KPS kelas ekperimen lebih tinggi dibandingkan kelas kontrol sehinnga dapat dismpulkan Scieintific Aproach with Guided Experiment efektif dalam memberdayankan kemampuan Keterampilan Peoses Sains siswa.
Perbedaan tersebut tentunya dikarenakan pada kelas ekperimen pemahaman mahsiswa mengenai konsep pada materi terbantu dengan pola pembelajaran dengan menggunakan Scieintific Aproach with Guided Experiment. Langkah-langkah Scieintific Aproach with Guided Experiment membantu siswa untuk berpikir menggunakan metode ilmiah secara sistematis. Pembelajaran mengarahkan pada siswa berhadapan dengan masalah yang dalam pemecahannya perlu pengujian dengan menggunakan kegiatan ekperimen (Isjoni, 2013). Siswa terlatih berpikir selayaknya ilmuwan karena dalam menentukan konsep melalui kegiatan yang sistemati seperti merumuskan masalah, berhipotesis, merancang percobaan, berekperimen hingga dapat mengkomunikasikan hasil sebagai solusi dari permasalahan yang ditemukan. Kegiatan belajar tersebut tentu mengarahkan mahasiswa untuk lebih terbiasa dan terampil dalam berproses sains sehingga KPS memiliki nilai yang optimal jika dibandingkan dengan kelas kontrol.

Hal ini ditunjukkan pada kelas eksperimen nilai KPS lebih tinggi dengan bantuan Guided Experiment siswa diajak untuk aktif dalam mengambangkan hands on dan minds on melalui menggunakan alat dan bahan kemudian cara kinerja pada lembar yang diberikan kepada siswa dapat dengan mudah siswa kerjakan sesuai dengan petunjuk yang terdapat pada lembar kerja siswa.

Segala (2010: 74) menyatakan bahwa berbagai hasil penelitian menyebutkan bahwa pendekatan keterampilan proses memiliki keunggulan diantaranya : 1) Memberi bekal cara memperoleh pengetahuan, 
Keterampilan proses merupakan hal yang sangat penting untuk pengembangan pengetahuan di masa depan, 3) Keterampilan proses bersifat kreatif, siswa aktif, dapat meningkatkan keterampilan berfikir dan cara memperoleh pengetahuan.

Peran serta guru dalam pembelajaran seharusnya sebagai pembimbing dan siswa menemukan sendiri konsep atau fakta yang akan dipelajarinya sehingga muncul sikap ilmiah siswa. Keterampilan proses penemuan sendiri akan lebih bermanfaat bagi siswa sehingga pengetahuan yang dimiliki sulit untuk dilupakan peserta didik. Perkembangan kognitif yang dihasilkan dari proses dialektika dimana seorang siswa yang belajar melalui pengalaman pemecahan masalah akan dipakai untuk saling berbagi dengan orang lain.

Penerapan pembelajaran dengan menggunakan Scieintific Aproach with Guided Experiment bertujuan agar siswa dapat terlibat langsung dalam kegiatan dan belajar untuk menyelesaikan masalah melaui langkah metode ilmiah yang diekpresikan melalui kegiatan praktikum. Siswa akan lebih mudah menerima materi karena siswa tidak perlu menghafal dan menulis materi tetapi dengan cara menyelidiki dan menemukan solusi dalam menyelesaikan suatu permasalahan sehingga daya ingat siswa akan lebih kuat.

Penggunaan Scieintific Aproach with Guided Experiment lebih banyak berpusat pada mahasiswa dibandingkan aktivitas pada pendekatan konvensional. Pendapat Lu dan Tseng (2007) menunjukkan bahwa tujuan pembelajaran sains tidak hanya untuk memperoleh penjelasan ilmiah yang ada, tetapi yang lebih penting, untuk membentuk ilmiah penjelasan melalui proses penyelidikan. Penjelasan menjelaskan hasil percobaan oleh siswa, berarti siswa datang untuk memahami bahwa pengetahuan ilmiah ada dalam hidup mahasiswa, dan dengan merefleksikan pengetahuan mahasiswa secara bertahap membentuk konsep-konsep ilmiah dan mengembangkan keterampilan untuk melakukan penyelidikan ilmiah. Siswa belajar untuk saling percaya berbagi sumber daya lain, dan memenuhi tanggung jawab mereka. Anak-anak yang memiliki keterampilan lebih dalam belajar juga menyebabkan mereka yang lemah dengan keterampilan untuk belajar dan menyelesaikan tugas bersama-sama dengan sikap positif (Lu dan Tseng, 2007).

Trianto (2014: 167), mengatakan bahwa ada beberapa kelebihan metode: 1) Metode ini dapat membuat siswa lebih percaya atas kebenaran atau kesimpulan berdasarkan percobaannya sendiri dari pada hanya menerima kata guru atau buku. 2) Siswa dapat mengembangkan sikap untuk mengadakan studi eksplorasi (menjelajahi) tentang ilmu dan teknologi. 3) Dengan metode ini akan terbina manusia yang dapat membawa terobosan-terobosan baru dengan penemuan sebagai hasil percobaan yang diharapkan dapat bermanfaat bagi kesejahteraan hidup manusia. 4) Siswa memperoleh pengalaman dan keterampilan dalam melakukan eksperimen. 5) Siswa terlibat aktif mengumpulkan fakta dan informasi yang diperlukan untuk percobaan. 6) Dapat menggunakan dan melaksanakan prosedur metode ilmiah dan berfikir ilmiah. 7) Dapat memperkaya pengalaman dan 
berpikir siswa dengan hal-hal yang bersifat objektif, realitas dan menghilangkan verbalisme. 8) Melalui eksperimen siswa dapat menghayati sepenuh hati dan mendalam, mengenai pelajaran yang diberikan. 9) Siswa dapat aktif mengambil bagian untuk berbuat bagi dirinya, dan tidak hanya melihat orang lain, tanpa dirinya melakukan. 10) Siswa dapat aktif mengambil bagian yang besar, untuk melaksanakan langkah-langkah dalam cara berpikir ilmiah. Halini dilakukan melalui pengumpulan datadata observasi, memberikan penafsiran serta kesimpulan.

Pembelajaran dengan menggunakan Scieintific Aproach with Guided Experiment memberikan pengaruh positif dari kenaikan skor rata-rata, sehingga nilai rata-rata siswa yang menggunakan Scieintific Aproach with Guided Experiment (kelas eksperimen) lebih baik dibandingkan siswa pada kelas kontrol. Scieintific Aproach with Guided Experiment mampu memfasilitasi siswa untuk memberdayakan KPS karena dalam tahapantahapan Scieintific Aproach with Guided Experiment siswa diarahkan untuk memecahkan permasalahan melalui kegiatan eksperimen agar menemukan solusi dari permasalahan hal ini didukung oleh Gallagher (2013) yang menyatakan bahwa penggunana Scieintific Aproach dalam pengelolaan kelas akan melatih siswa besikap ilmiah dengan membiasakan siswa untuk berinvestigasi menemukan pemecahan masalah dari permasalahan yang diberikan dan membiasakan diri berlaku sebagai ilmuwan. Siswa terbiasa mencari dan menemukan sendiri solusi hasil dari penmuan-penemuan yang dilakukan.

\section{SIMPULAN}

Berdasarkan hasil penelitian dan pembahasan dapat dismpulkan bahwa Scieintific Aproach with Guided Experiment lebih efektif dalam memberdayakan kemampuan Keterampilan Proses Sains. Berdasarkan hasil uji ada perbedaan kemampuan Keterampilan Proses Sains siswa pada kelas eksperimen dan kelas kontrol. Hal ini terbukti dari pengujian statistik diperoleh adanya perbedaan KPS siswa, dengan hasil $p=0,000$ dan nilai $t_{\text {hitung }}=0,018$. Kelas yang menerapkan Scieintific Aproach with Guided Experiment memiliki rata-rata KPS lebih tinggi dibandingkan kelas tanpa menggunakan Scieintific Aproach with Guided Experiment yaitu sebesar 82,34 dan 71,14.

\section{DAFTAR PUSTAKA}

Amita, Pinkan.2016. Efektivitas Scieintific Aproach pada Pembelajaran Sains dengan Setting PBL untuk Memberdayakan Science Process Skil. Jurnal Bioedukasi. Pendidikan Biologi Universitas Sebelas Maret. Vol 8. No 1.

Capay, M dan Magdin, M (2013) Task For Teaching Scientific Approach Using The Black Box Method. Jurnal Departement of Informatics Faculty of Natural Sciencies, Constantine the Philospher Universitas in Nitra. Slovakia 
Isjoni. 2013. Cooperative Learning (Efektifitas Pembelajaran Kelompok). Bandung: Alfabeta

Lu, C., Hong, J., \& Tseng, Y. 2007. The Effectiveness Of Inquiry-Based Learning By Scaffolding Students To Ask “5 Why” Questions. Jurnal Pendidikan, vol. 1, no. 26.

Permendiknas. 2006. Standar Isi dan Standar Kompetensi Lulusan untuk Satuan Pendidikan Dasar SD/MI. Jakarta: Cipta Jaya.

PISA. 2009. Ranking by Mean Score for Reading, Mathematics and Science. Online(http://www.pisa.oecd.org/pages/0,3417,en322523513223573111111,00.html Diakses 21 Desember 2016).

TIMSS. 2011. TIMSS and PIRLS in 2011Development Completed-Into the Field!.TIMSS \& PIRLS International Study Center, Lynch School of Education, Boston College. IEA International Association for the Evaluation of Educational Achievement. Online (http://www.iea.nl. Diakses 21 Desember 2016).

Sanjaya, Wina. 2012. Strategi Pembelajaran Berorientasi Standar Proses Pendidikan. Jakarta: Prenada Media Grup.

Trianto. 2013. Mendesaign Model Pembelajaran Inovatif Progresif. Jakarta: Kencana

Trianto. 2014. Model Pembelajaran Terpadu: Konsep Strategi, dan Implementasinya dalam kurikulum Tingkat Satuan Pendidikan (KTSP). Jakarta: Bumi Aksara.

Wenning, C.J. 2008. "Dealing More Effectively with Alternative Conception in Science". Journal Phisics Teacher Education, Volume 5, Nomor 1. hlm.11-19. 